\title{
Correction to: The Nutrition-COVID-19 Interplay: a Review
}

\author{
Janet Antwi ${ }^{1} \cdot$ Bernard Appiah $^{2} \cdot$ Busayo Oluwakuse ${ }^{1} \cdot$ Brenda A. Z. Abu ${ }^{3}$ \\ Published online: 14 December 2021 \\ (c) Springer Science+Business Media, LLC, part of Springer Nature 2021
}

\section{Correction to: Current Nutrition Reports}

https://doi.org/10.1007/s13668-021-00380-2

In this article, the affiliation details for Author "Brenda A. Z. Abu" were incorrectly given as "Wegmans School of Health and Nutrition, College of Health Sciences and Technology, Rochester, NY, USA" but should have been "Wegmans School of Health and Nutrition, College of Health Sciences and Technology, Rochester Institute of Technology, Rochester, NY, USA."

Publisher's Note Springer Nature remains neutral with regard to jurisdictional claims in published maps and institutional affiliations.

The original article can be found online at https://doi.org/10.1007/ s13668-021-00380-2.

Janet Antwi

jaantwi@pvamu.edu

1 Department of Agriculture, Nutrition and Human Ecology,

Prairie View A\&M University, Prairie View, TX, USA

2 Department of Public Health, Syracuse University, Syracuse, NY, USA

3 Wegmans School of Health and Nutrition, College of Health Sciences and Technology, Rochester Institute of Technology, Rochester, NY, USA 